\title{
Ectopic Decidua Presenting With a Sigmoid Bowel Perforation: A Case
} Report

\author{
Audrius Gradauskas ${ }^{1,2^{*}}$, Jonas Činčikas ${ }^{2}$, Ričardas Daunoravičius ${ }^{3}$, Ugnius Mickys ${ }^{6}$, Giedrius Mazarevičius ${ }^{2}$, leva Šataitė ${ }^{2}$, Valdemaras $^{2}$ \\ Jotautas ${ }^{4}$, Dileta Rutkauskaitė ${ }^{5}$, and Kęstutis Strupas ${ }^{4}$
}

${ }^{1}$ Department of Nursing and Fundamentals of Internal Medicine, Faculty of Medicine, Vilnius University, Universiteto g.3, LT-01513, Vilnius, Lithuania

${ }^{2}$ Department of Abdominal Surgery, Vilnius City Clinical Hospital, Antakalnio g. 57, LT-10207, Vilnius, Lithuania

${ }^{3}$ Second Department of Obstetrics, Vilnius City Clinical Hospital, Antakalnio g. 57, LT-10207, Vilnius, Lithuania

${ }^{4}$ Clinic of Gastroenterology, Nephrourology and Surgery, Faculty of Medicine, Vilnius University, Lithuania

${ }^{5}$ Department of Radiology, Nuclear Medicine and Medical Physics, Faculty of Medicine, Vilnius University, Lithuania

${ }^{6}$ National Pathology Center, P. Baublio 5, LT-08406, Vilnius, Lithuania

\begin{abstract}
The occurrence of ectopic decidua has been observed mostly in the ovaries, uterus and cervix. Ectopic gastrointestinal deciduosis is a physiological condition. Only several cases of ectopic decidua, causing complications have been presented in literature. To the best of our knowledge, sigmoid or any other bowel perforation, caused by deciduosis, has not been previously reported in literature.
\end{abstract}

Case presentation: A 40-year old patient primigravida (32 weeks of gestation) was admitted with a severe abdominal pain and obstipation. An abdominal sonography was performed but no visual cause of the pain was diagnosed. Two days after admission the episode of severe pain reappeared. An abdominal sonography and $\mathrm{x}$-ray showed "free air" under both domes of diaphragm. A laparotomy was performed. No perforation of hollow viscus was found. On the fifth postoperative day, the patient started to complain about acute abdominal pain. The decision was made to perform relaparotomy (a Caesarean section and reexploration of abdominal cavity during the same operation). During the relaparotomy a part of sigmoid colon was visually altered. A microperforation on tumour-like structures was found in the sigmoid colon. A Sigmoid resection was performed. Currently the patient has no residual complaints and is enjoying her motherhood.

Conclusion: We assert that ectopic decidua can result in a perforation of the hollow viscus, which is a lifethreatening condition and should always be taken into account seriously. We believe that sigmoid microperforation could have found, we had taken a more aggressive approach and performed a Caesarean section during the first operation.

Keywords: Deciduosis; Complications; Sigmoid colon perforation

Abbreviations: ICU: Intensive Care Unit

\section{Introduction}

The first case of ectopic (extrauterine) decidua was described by Walker [1]. The occurrence of ectopic decidua has been observed mostly in the ovaries, uterus and its cervix. Usually ectopic extrauterine deciduosis appear during pregnancy. However, cervical and ovarian decidual lesions may appear in non-pregnant patients, mostly in relation to gestagen therapy or even without it. A peritoneal localization is less frequent and usually is an asymptomatic incidental finding $[2,3]$. Ectopic gastrointestinal deciduosis is a physiological condition hypothetically resulting from progesterone-induced metaplasia of the subserosal cells [4]. Only several cases of ectopic decidua causing complications, such as intra-abdominal bleeding [5] or obstruction of labour [6], severe abdominal pain similar to the pain of appendicitis or mechanical bowel obstruction [7] were presented in literature. To the best of our knowledge, sigmoid or any other bowel perforation has not been previously reported. Tumour-like and mass forming intraperitoneal ectopic deciduosis of the pregnant patient with deep invasion to sigmoid colon causing perforation with favorable outcome is presented in this case report.

\section{Case Presentation}

A 40-year-old primigravida patient (32 weeks of gestation) was admitted to the Department of Obstetrics with severe abdominal pain on the right side of the abdomen and obstipations; the patient did not have nausea or vomiting. The patient upon the admission was consulted by an abdominal surgeon and urologist. An abdominal sonography was performed but no visual cause of the pain was observed. Laboratory tests showed elevated white blood cells count (WBC $\left.-12 \times 10^{9} / 1\right)$ and C-reactive protein (CRP $-54.06 \mathrm{mg} / \mathrm{l})$. After administering intravenous fluids and analgetics her condition improved.

Two days after the admission the episode of severe pain reappeared. The second abdominal sonography was performed. "Free air" under both domes of diaphragm was found. Abdominal X-ray confirmed the diagnosis.

The patient was transferred to the Department of Abdominal Surgery and was operated upon. An upper-middle laparotomy was performed since perforated duodenal ulcer was suspected. As no perforation could be found, intraoperative upper endoscopy and water-air test were performed (both negative). Without being able to determine the cause of "free air" in the abdominal cavity, the operation was terminated. The drain was left in subhepatic space.

After the operation the patient was treated in the ICU. During the

*Corresponding author: Dr. Audrius Gradauskas, Department of Nursing and Fundamentals of Internal Medicine, Faculty of Medicine, Vilnius University, Universiteto g.3, LT-01513, Vilnius, Lithuania, Tel: +370 685 44800; Fax: +370 5 2346966; E-mail: audrius.gradauskas@yahoo.com

Received June 02, 2012; Accepted July 06, 2012; Published July 08, 2012

Citation: Gradauskas A, Činčikas J, Daunoravičius R, Mickys U, Mazarevičius G, et al. (2012) Ectopic Decidua Presenting With a Sigmoid Bowel Perforation: A Case Report. J Clin Case Rep 2:168. doi:10.4172/2165-7920.1000168

Copyright: (C) 2012 Gradauskas A, et al. This is an open-access article distributed under the terms of the Creative Commons Attribution License, which permits unrestricted use, distribution, and reproduction in any medium, provided the original author and source are credited. 
following four days the patient's condition did not have any negative dynamics. She was treated with Ceftriaxon $2 \mathrm{~g} 2$ times per day, Metronidazole $500 \mathrm{mg} 3$ times per day, intravenous fluid infusions, anticoagulants (Fraxiparine $0.2 \mathrm{mg}$ daily). CRP`s level normalized, as well as WBC count and no fever was observed.

On the fifth postoperative day our patient started to complain about acute abdominal pain again. It was localized in the left lower part of the abdomen. Laboratory findings showed increased CRP $(209 \mathrm{mg} / \mathrm{l})$ and WBC $\left(2325 \times 10^{9} / 1\right)$ count. The decision was made to perform a Caesarean section and re-exploration of abdominal cavity.

A baby girl was born. Apgar score was 8 at 1 minute and 10 at 10 minutes after the delivery. During the relaparotomy, small amount of fibrin threads were observed in the minor pelvis. Approximately 20-25 centimeters of sigmoid colon were altered: the intestinal wall was thickened and covered with soft tumour-like tissue. No bowel perforation was observed. Intraoperative cold section biopsy was taken. The result was "myxoid-like tissue with smooth muscle miocytes". There was not enough data to confirm a tumour. Saline solution was poured into the abdominal cavity and air was pumped through the anus. Eventually bubbles were observed from a microperforation in one of the tumour-like structures. Because the changes in the sigmoid were tumour-like, without having been able to deny the possibility of malignancy, a sigmoid resection was performed. The descending colon was anastomosed with the rectum, the abdominal cavity was drained.

The postoperative period was smooth, without any complications. The patient was followed-up for fifteen months after the second operation. No complications were observed at the time. Currently the patient has no residual complains, she is breastfeeding and enjoying her motherhood.

\section{Pathology}

Macroscopy: Dark, red, soft nodules in the submucosa, muscular is propria, subserosa of the resected large bowel. Identical exophytic nodules in subserosal space of the small bowel and uterus (biopsies) (Figure 1).

Methods: All specimens were fixed in 10\% buffered formalin, embedded in paraffin. $4 \mu \mathrm{m}$ sections were stained with haematoxylineosin ( $3 \mu \mathrm{m}$ sections used for immunohistochemistry). Immunostaining was performed with antibodies for Pan Cytokeratin Dako; dilution

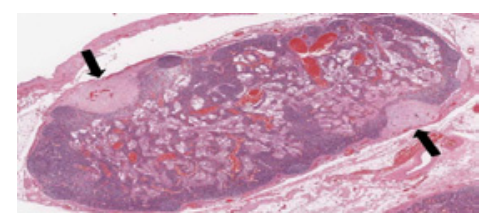

Figure 1: Resected large bowel with polypoid dark red colored exophytic masses in the subserosal space.

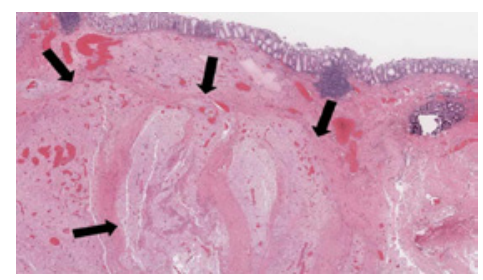

Figure 2: HE 1.5x. Large bowel's wall with ectopic decidual nodules in the subserosa, muscularis propria and submucosa (arrows).

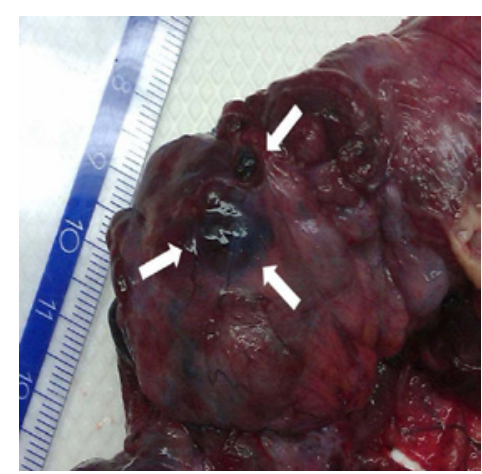

Figure 3: HE 2x. Ectopic decidual nodules in the sinuses of the lymph node (arrows).

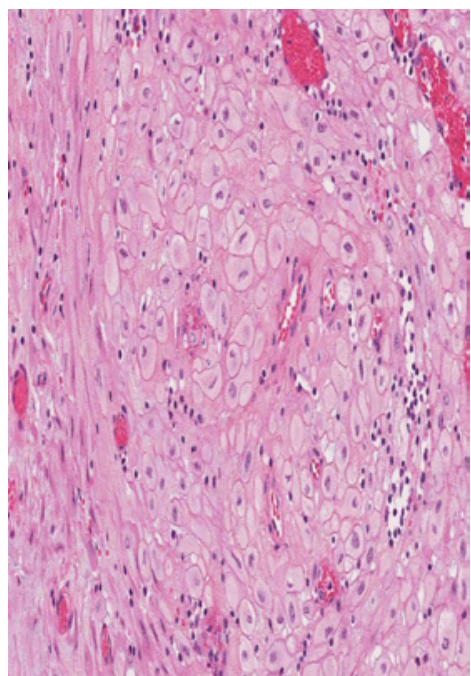

Figure 4: HE 20x. Decidual nodule in the large bowel's wall: The large cells with glassy eosinophilic cytoplasm and distinct borders within capillarised stroma.

1:100; EDTA Ag retrieval), Vimentin (Dako; dilution 1:800; EDTA Ag retrieval), Ki67 (Dako; dilution1:200; EDTA Ag retrieval), ER/ PR (Ventana; ready for use; Ag retrieval solution CC1), Calretinin (Dako; dilution 1:30; EDTA Ag retrieval ), Placental alkaline phosphatase (Dako; dilution 1:40; EDTA Ag retrieval), Cytokeratin 5 (DAKO; dilution 1:100; EDTA Ag retrieval).

Histology: The sigmoid colon showed the ectopic decidua confluent nodules in subserosa, muscularis propria and submucosa, composed of large polygonal cells with glassy eosinophilic cytoplasm with distinct borders (Figure 2,4). Identical nodules were found within sinuses in the pericolonic lymph nodes (Figure 3), uterine and small intestines subserosal space (biopsies were taken from these parts too). The decidual foci showed typical immunoprofile: progestine receptors (PR) /Vimentin diffusely positive, estrogen receptors (ER) focally positive. Ki67 proliferative index was very low $<1 \%$. Pancytokeratin, Calretinin, Placental alkaline phosphatase and Cytokeratine 5 stains were negative.

\section{Discussion}

Ectopic deciduosis is a known phenomenon, described in different locations as cervix uteri [8], ovary [9], fallopian tubes, appendix [10] peritoneum [6], omentum [4], diaphragm, liver, spleen, pleura [11], lymph nodes [12], renal pelvis [13], skin [14]. 
Clinically extra uterine ectopic deciduosis may easily simulate disseminated tuberculosis [3] or metastatic disease [2].

In some rare cases (such as ours) extrauterine deciduosis may simulate primary neoplastic growth, forming large polypoid nodules usually in subserosal space or even in the deep tissues of visceral organs.

The main differential diagnosis of ectopic tumour-like deciduosis should be with rare malignant deciduoid mesothelioma, which arises commonly in the peritoneum of young women [15]. In our case the nodules of deciduosis, despite infiltrative and deep growth pattern, spreads serosal surface differently, than mesothelioma. The immunoprofile of deciduosis cells was different: CK5 and Calretinin negative and estrogen/progesterone receptors positive. Low Ki67 proliferative index, rare mitoses serve as additional argument against mesothelioma diagnosis. The macroscopy of the deciduosis lesions (hemorrhagic dark red nodules) was different from white and firm nodules/plagues in mesothelioma cases. Metastatic carcinomas are usually pan cytokeratin positive and display more atypical cytological features. It is interesting that in rare cases deciduosis masses may be cytokeratin positive, too. Therefore, our findings were in line with immunoprofile described in decidual cells [16].

The deep seated deciduosis masses may complicate the labour [6], cause serious complications, such as appendiceal perforation, acute bowel obstruction [17], intraperitoneal hemorrhage [19], peritonitis, adhesions. Even fatal outcome was observed [19].

In our case, due to pregnancy and enlarged uterus, there was no possibility to visualize and explore the suppositional perforation area in the minor pelvis during the first operation.

Although there are opinions that deciduosis does not need any therapeutic interventions or operations and it regresses postpartum without any complications [7], in our case this does not apply, because the patient could have died without an appropriate operation.

\section{Conclusion}

In our case the wall of sigmoid colon was deeply infiltrated by deciduosis nodules and became fragile. We can speculate that mechanical pressure from pregnant uterus together with intracolonic gas pressure caused sigmoid rupture with the clinical course described above.

We believe that sigmoid microperforation could have been found had we taken a more aggressive approach and performed a Cesarean section during the first operation. Various ways to find the perforation were used but none was successful. However, speculating about these reasons has little meaning. We hereby state that ectopic decidua can result in a perforation, which is a life-threatening condition and should always be taken into account seriously.

\section{References}

1. Walker A (1887) Der Bau der Eihäute Graviditatis abdominalis. Virch Arch Path Anat 197: 72-99.

2. Piccinni DJ, Spitale LS, Cabalier LR, Dionisio de Cabalier ME (2002) [Decidua in the peritoneal surface mimicking metastatic nodules. Findings during cesarean section]. Rev Fac Cien Med Univ Nac Cordoba 59: 113-116.

3. Shukla S, Pujani M, Singh SK (2008) Ectopic decidual reaction mimicking peritoneal tubercles: a report of three cases. Indian J Pathol Microbiol 51: 519520 .

4. Buttner A, Bassler R, Theele C (1993) Pregnancy-associated ectopic decidua (deciduosis) of the greater omentum. An analysis of 60 biopsies with cases of fibrosing deciduosis and leiomyomatosis peritonealis disseminata. Pathol Res Pract 189: 352-359.
5. Sabatelle R, Winger E (1973) Postpartum intraabdominal hemorrhage caused by ectopic deciduosis. Obstet Gynecol 41: 873-875.

6. Malpica A, Deavers MT, Shahab I (2002) Gross deciduosis peritonei obstructing labor: a case report and review of the literature. Int J Gynecol Pathol 21: 273275

7. Bloom SL, Uppot R, Roberts DJ (2010) Case records of the Massachusetts General Hospital. Case 32-2010. A pregnant woman with abdominal pain and fluid in the peritoneal cavity. N Engl J Med 363: 1657-1665.

8. Le Coz A, Mazerolles J, Masson M (1967) [8 cases of deciduosis of the uterine cervix]. Rev Fr Gynecol Obstet 62: 535-539.

9. Sammour RN, Leibovitz Z, Shapiro I, Degani S, Levitan Z, et al. (2005) Decidualization of ovarian endometriosis during pregnancy mimicking malignancy. J Ultrasound Med 24: 1289-1294.

10. Hauptmann J, Mechtersheimer G, Blaker H, Schaupp W, Otto HF (2000) [Deciduosis of the appendix. Differential diagnosis of acute appendicitis] Chirurg 71: 89-92.

11. Flieder DB, Moran CA, Travis WD, Koss MN, Mark EJ (1998) Pleuro-pulmonary endometriosis and pulmonary ectopic deciduosis: a clinicopathologic and immunohistochemical study of 10 cases with emphasis on diagnostic pitfalls. Hum Pathol 29: 1495-1503.

12. Wu DC, Hirschowitz S, Natarajan S (2005) Ectopic decidua of pelvic lymph nodes: a potential diagnostic pitfall. Arch Pathol Lab Med 129: e117-120.

13. Bettinger HF (1947) Ectopic decidua in the renal pelvis. J Pathol Bacteriol 59: 686

14. Fair KP, Patterson JW, Murphy RJ, Rudd RJ (2000) Cutaneous deciduosis. J Am Acad Dermatol 43: 102-107.

15. Mourra N, de Chaisemartin C, Goubin-Versini I, Parc R, Flejou JF (2005) Malignant deciduoid mesothelioma: a diagnostic challenge. Arch Pathol Lab Med 129: 403-406.

16. Heatley MK, Maxwell P, Toner PG (1996) The immunophenotype of human decidua and extra-uterine decidual reactions. Histopathology 29: 437-442.

17. Heidegger H, Humpfner A, Hugo R, Schulz W (1991) [Peritoneal deciduosis: cause for mechanical ileus in pregnancy]. Geburtshilfe Frauenheilkd 51: 307 309 .

18. O'Leary SM (2006) Ectopic decidualization causing massive postpartum intraperitoneal hemorrhage. Obstet Gynecol 108: 776-779.

19. Theissig F, Kemmer C, Kunze KD (1988) [Fatal course of mesenteric deciduosis in a gravida I]]. Pathologe :50-54. 